\title{
SOCIABILIDAD CORTESANA Y MODELOS DE MONARQUÍA EN ESPAÑA (1833-1872)
}

\author{
Raquel Sánchez \\ (Universidad Complutense de Madrid) \\ raquelsg@ucm.es
}

\section{RESUMEN}

Este trabajo reflexiona acerca de la importancia de la sociabilidad cortesana para estudiar tres cuestiones de interés: la legitimación social de las elites a través de su relación con la monarquía; la sociabilidad cortesana como reflejo de dos formas de entender la monarquía en la España del siglo XIX; y la sociabilidad cortesana como vía para explorar el papel del monarca en el espacio público en tanto que símbolo de la nación. Para ello se comparan los reinados de Isabel II y de Amadeo de Saboya.

PALABRAS CLAVE: Sociabilidad; Monarquía; Corte; Nacionalización; Isabel II

\section{COURTLY SOCIABILITY AND MODELS OF MONARCHY IN SPAIN}

(1833-1872)

\begin{abstract}
Through the comparison of the reigns of Isabel II and Amadeo de Savoie, this work deals with the importance of courtly sociability to study three issues of interest. First, the social legitimization of the elites through their relationship with the monarchy. Second, the role of courtly sociability as a reflection of two ways of understanding the monarchy in nineteenth-century Spain. Finally, courtly sociability as a way to explore the role of the monarch in public space as a symbol of the nation.
\end{abstract}

KEYWORDS: Sociability; Monarchy; Court; Nationalization; Isabel II.

Más allá de la consideración de la Casa Real como un entorno administrativo dedicado al servicio y cuidado del monarca y su familia, la corte es también un espacio social cuyas reglas merece la pena estudiar para entender que ese 
microcosmos refleja muchos aspectos de la vida social y política de un país ${ }^{1}$. Pudiera parecer que, con el desarrollo del Estado liberal, la corte, asociada a las tradicionales formas de entender la relación entre el monarca y sus súbditos, perdió su trascendencia y se convirtió en un espacio en el que unos individuos con título nobiliario rodeaban al monarca para continuar reproduciendo ciertos rituales ceremoniales. Por otra parte, las connotaciones negativas asociadas a las palabras «cortesano» y «camarilla» han contribuido a simplificar el análisis de este objeto de estudio y sus múltiples derivaciones. Sin embargo, lo que parece evidente al acercarse a las fuentes es que la corte se adaptó a la nueva realidad sociopolítica convirtiéndose en un espacio de poder que, en algunos reinados y en algunos momentos, tuvo un papel muy importante ${ }^{2}$. La corte desaparecerá en España en 1931 y no volverá a existir como tal tras la muerte del general Franco y el retorno de la monarquía, a pesar de que el símil cortesano haya sido, y siga siendo, utilizado por la prensa y los analistas políticos para describir a los amigos y amigas de los reyes eméritos y de los reyes actuales. Si la metáfora cortesana continúa teniendo vigencia es porque el público cree ver en estos amigos del rey a individuos que, si bien ya no desempeñan las funciones de servicio palaciego de los antiguos cortesanos, también en la actualidad se mueven por intereses que persiguen objetivos privados, sirviéndose, en teoría, de su amistad con la jefatura del Estado. Todo ello se realizaría en situaciones en las que la relación personal, liberada de las obligaciones cortesanas, se entabla en entornos de sociabilidad lúdica, ya sean deportivos, festivos, culturales, etc. Si esto sucede en la actualidad, en que los mecanismos de control político de este tipo de actividades son más estrictos, hemos de plantearnos cuál fue su dimensión en el pasado. Por eso puede decirse que la sociabilidad en el entorno de la corte alcanza un papel muy importante para entender el desenvolvimiento de la vida política de la España liberal y, en particular, durante dos momentos especialmente significativos: los reinados de Isabel II y de Alfonso XIII.

En este trabajo se va a seguir un desarrollo que, en primer lugar, nos permita entender las líneas generales de lo que podríamos denominar la «sociabilidad cortesana», teniendo en cuenta que Madrid, capital y corte, es el escenario principal de estas actividades. Para ello se plantearán unas observaciones que solo pretenden aproximarse a un tema sobre el que queda aún mucho por estudiar, pero que pueden ayudar a desbrozar el camino. En segundo lugar, se aplicarán estas observaciones al reinado de Isabel II, prestando atención no solo a las prácticas de sociabilidad desarrolladas alrededor de la reina, sino también a lo que fue una corte paralela: la de su madre María Cristina, hasta su marcha de España tras la revolución de 1854. Finalmente, y a modo de contraste, se harán algunas referencias a las prácticas de sociabilidad, más bien a la escasez de las mismas, en la corte del rey Amadeo de Saboya, pues constituye un ejemplo claro que hasta qué punto las actividades

\footnotetext{
${ }^{1}$ Este trabajo se integra en el proyecto de investigación "Corte, Monarquía y Nación liberal (18331885). En torno al Rey y la modernización política de España en el siglo XIX” (HAR2015-66532-P) (MINECO/FEDER).

${ }^{2}$ Véase: Raquel Sánchez, ed., El Poder informal: la corte como escenario Político en España (1833-1885), Aportes. Revista de Historia Contemporánea, 33/96 (2018).
} 
mundanas llegaron a alcanzar un significado político de primera magnitud durante este reinado. Se trata, por tanto, de un análisis general, macro, que únicamente pretende plantear puntos de partida que permitan profundizar en un tema como es el de la sociabilidad de las clases altas en la España del siglo XIX. A la historiografía le ha interesado más la Restauración por la existencia de fuentes solventes, como las derivadas de la figura periodística del cronista de sociedad, que tanta popularidad habría de tener entre finales del siglo XIX y principios del $\mathrm{XX}^{3}$.

\section{¿CÓMO ENTENDER LA SOCIABILIDAD CORTESANA?}

La primera pregunta que habría que hacerse es a qué hacemos referencia cuando hablamos de sociabilidad cortesana. Incluso, cabría reflexionar acerca de dicha expresión, si es la más adecuada o si tal vez sería necesario precisar más, ya que, como veremos, nos vamos a referir a distintas realidades. Al adentrarnos en el estudio de las monarquías posrevolucionarias, la centralidad otorgada por Norbert Elias al mundo cortesano en el proceso de concentración del poder alrededor del monarca presenta dificultades de encaje por los desafíos al poder real y al origen de su soberanía que planteó el liberalismo ${ }^{4}$. Las limitaciones al poder real no implicaron una reducción de la capacidad de influencia del entorno cortesano sobre la sociedad burguesa y, en particular, sobre las clases emergentes. De ahí que pueda afirmarse que cuando nos aproximamos al estudio de la corte desde una perspectiva sociológica, no nos estemos enfrentando a un ambiente en decadencia, sino a un mundo capaz de generar un efecto imitador en las clases altas ${ }^{5}$. Reflejo de conductas y prácticas del pasado, el mundo cortesano fue capaz de mantener y fomentar las actitudes aristocráticas y las jerarquías heredadas del Antiguo Régimen que, si bien no podían interesar a la sociedad y a la cultura política más progresista, ejercieron una irresistible atracción en los grupos ascendentes o, simplemente, en una sociedad que aún compartía una cosmovisión anclada en pilares preliberales.

Una de las cuestiones que hay que tener en cuenta en una primera aproximación al tema es la dualidad de contextos en los que tiene lugar la sociabilidad cortesana. Por una parte, nos encontramos con situaciones que se enmarcan en actos regidos por un estricto protocolo y que tienen que ver con ceremonias relacionadas

\footnotetext{
${ }^{3}$ Con un importante precursor, Ramón de Navarrete, «cronista de salones» de La Época, periódico del que llegó a ser director y donde publicó su primer artículo de sociedad en 1849. El más famoso cronista de sociedad de la Restauración fue Eugenio Rodríguez Ruiz de la Escalera (Monte Cristo), que trabajó para Blanco y Negro. Su libro Los salones de Madrid (1898) es una obra fundamental para el estudio de estas cuestiones. En España, la sociabilidad aristocrática ha sido estudiada por María Zozaya en El Casino de Madrid: ocio, sociabilidad, identidad y representación social (Madrid: UCM, 2008) y por Cristina del Prado en El todo Madrid. La corte, la nobleza y sus espacios de sociabilidad en el siglo XIX (Madrid: Fundación Universitaria Española, 2012).

${ }^{4}$ Norbert Elias, La sociedad cortesana (Madrid: FCE, 1993). El modelo analítico de Elias, como es sabido, está focalizado en el estudio de las monarquías barrocas y, en especial, la Francia de Luis XIV.

${ }^{5}$ Este fenómeno, ya estudiado por Arno J. Mayer (La persistencia del Antiguo Régimen) ha sido documentado para el caso español por Jesús Cruz en El surgimiento de la cultura burguesa. Personas, hogares y ciudades en la España del siglo XIX (Madrid: Siglo XXI, 2014).
} 
con la Corona; con la Corona y las instituciones representativas y de gobierno; y con la Corona y la Iglesia. Por otra parte, hallamos situaciones en las que el protocolo es más flexible y que suelen estar relacionadas con el ocio. Me referiré a las primeras con la expresión de sociabilidad formal y a las segundas con la de sociabilidad informal, haciendo constar que, pese a todo, y cuando los monarcas formaban parte de un acto público o privado, la etiqueta y las normas protocolarias siempre regían estos encuentros, en mayor o menor grado ${ }^{6}$. El rey o la reina solo podían liberarse de este rígido corsé en la más estricta intimidad, algo que resultaba complicado para una función, la del monarca, en la que las fronteras entre lo íntimo, lo privado y lo público no estaban claramente delimitadas. Al fin y al cabo, el monarca era una institución del Estado a lo largo de todas las horas del día. Aunque no es este el lugar para reflexionar sobre ello, esta observación resulta muy interesante si la trasladamos a la realidad de las monarquías del siglo XXI, en las que se evidencia de forma clara el deseo de privacidad de unos individuos (los monarcas contemporáneos) que, precisamente por el carácter simbólico de lo que representan, no se encuentran en disposición de reclamar algo que es ajeno a su condición. Desde el siglo XIX, en Europa el monarca es una figura pública, cabeza e imagen de la nación y, por tanto, encarnación moral de la misma.

La sociabilidad formal, es decir, la que se halla regida por la etiqueta y el protocolo, ha sido denominada por Francisco Villacorta «sociabilidad cortesana representativa», siguiendo los planteamientos de Elias al respecto ${ }^{7}$. Se refiere el profesor Villacorta a la importancia que, desde las monarquías barrocas, tuvieron los ceremoniales asociados a la Corona y, sobre todo, al carácter representativo de estos. La fiesta barroca se plasma, de este modo, en las actividades que refuerzan el significado simbólico de la institución a través de la ritualización de las ceremonias. La etiqueta y el protocolo marcan, de esta forma, los tiempos y el camino a seguir; indican el lugar en el que se celebran los actos; ubican a los participantes en el lugar que les corresponde socialmente; dictaminan las vestimentas que se han de llevar en

\footnotetext{
${ }^{6}$ La historiografía y la sociología han estudiado a fondo a qué contextos y situaciones debemos aplicar el concepto de «sociabilidad». Por sociabilidad formal se suele hacer referencia al estudio de fenómenos como el asociacionismo y no a estas prácticas protocolarizadas que son las ceremonias. Sin embargo, y para el análisis específico de la sociabilidad cortesana, considero muy operativo utilizar el calificativo de «formal» en contraste con otras manifestaciones de la interactuación entre los agentes del entorno cortesano. Algunas reflexiones, sin ánimo de exhaustividad, sobre el fenómeno de la sociabilidad en: Maurice Agulhon, Politica, imágenes, sociabilidades de 1789 a 1989 (Zaragoza: Prensas de la Universidad de Zaragoza, 2016), en particular: «¿Es la sociabilidad un objeto histórico?», pp. 103-118, y El círculo burgués. La sociabilidad en Francia, 1810-1848 (Buenos Aires: Siglo XXI, 2009). Para el caso español: J.-L. Guereña, «Espacios y formas de la sociabilidad en la España contemporánea. Introducción», Hispania, 214 (2003), pp. 409-414; Carmen de la Guardia Herrero, «Las culturas de la sociabilidad y la transformación de lo político», en María Cruz Romeo, y María Sierra, (coords.), La España Liberal, 1833-1874, (Madrid: Marcial Pons-Prensas de la Universidad de Zaragoza, 2014); Elena Maza Zorrilla, (coord.), Sociabilidad en la España Contemporánea. Historiografía y problemas metodológicos (Valladolid: Universidad de Valladolid, 2002); Ramón Arnabat, y Montserrat Duch, (coords.), Historia de la sociabilidad contemporánea. Del asociacionismo a las redes sociales (Valencia: Universitat de València, 2014).

${ }^{7}$ F. Villacorta, «Sobre un viejo escenario: reina, corte y cortesanos en representación», Isabel II: los espejos de la reina, ed. J.S. Pérez Garzón (Madrid, Marcial Pons, 2004), 282-297.
} 
función del rango que se ocupa en la sociedad cortesana; pautan los momentos de silencio, los momentos de escucha y los momentos de conversación, etc. Todo ello en una dialéctica de alejamiento y aproximación de la figura del monarca a sus súbditos que tiene como objetivo, en palabras de Walter Bagehot, mantener el «encantamiento místico» de la monarquía ${ }^{8}$. Sin embargo, con el fin de las monarquías absolutas y la consagración de la soberanía compartida como dogma de la modernidad política en las monarquías posrevolucionarias de la Europa occidental, el papel jugado por las ceremonias asociadas a la monarquía habría de reformularse e, incluso, reforzarse al quedar la monarquía rebajada en su poder efectivo. El objetivo era claro y, de nuevo recurriendo a Bagehot, había que evitar la «erosión continuada de la monarquía mágica por los aspectos más prácticos». Disociado de los partidos políticos y las mayorías resultantes de los procesos electorales, el monarca se apoyaba en su naturaleza simbólica para expresar la continuidad histórica de la nación. De este modo, la ceremonia barroca se transmutaba en la celebración de la continuidad de una institución que era la nación misma en sus diversas encarnaciones temporales. Dado que en las monarquías liberales europeas son las ceremonias las expresiones más evidentes de la exteriorización del carácter emblemático de la figura del monarca, resulta factible, por tanto, establecer una equivalencia entre la «sociabilidad formal» y la «sociabilidad ceremonial» de la que habla Villacorta, pues ambas expresiones permiten referirse a la amplia variedad de ritos y celebraciones que nos encontramos en la Europa del siglo XIX y que van desde las tradicionales solemnidades barrocas hasta las más modernas ceremonias asociadas al sistema político representativo, como la apertura de las Cortes. De esta forma, es posible enlazar con el concepto de performing monarchy, la monarquía escénica que, través de los procesos ceremoniales y otros rituales simbólicos, persigue distintos objetivos, que van desde la legitimación de una dinastía hasta la encarnación de la nación en la persona del monarca?.

Por otra parte, en el estudio de la sociabilidad cortesana de las monarquías liberales del siglo XIX ha de prestarse atención especial a los espacios en los que se realizan esas actividades sociales. El lugar de celebración de dichas reuniones es significativo porque marca de forma clara la naturaleza de las mismas. Ciertamente, las más importantes, las más asociadas a la sociabilidad ceremonial, son las celebradas en el Palacio Real y, secundariamente, en los Sitios Reales. Dentro del propio Palacio Real, incluso, pueden diferenciarse espacios o situaciones más propicios a la sociabilidad formal que otros. Los usos de la antecámara real son un buen ejemplo de

${ }^{8}$ Walter Bagehot, The English Constitution (Londres: Chapman and Hall, 1867). Fue traducido al español por Adolfo Posada en 1902 para La España Moderna. Un análisis contemporáneo en Martin Kirsh, «La trasformazione politica del monarca europeo nel XIX secolo», Scienzia \& Politica, 34 (2006): 22-35.

${ }^{9}$ La bibliografía al respecto es muy amplia, desde el ya clásico texto de David Cannadine («Contexto, representación y significado del ritual: la monarquía británica y la invención de la tradición, c. 1820-1977») hasta el más reciente trabajo de Xavier Mauduit, Le Ministère du faste. La Maison de l'empereur Napoléon III (Paris: Fayard, 2016). Un estado de la cuestión, con reflexiones sobre el caso español, en David San Narciso, «Ceremonias de la monarquía isabelina. Un análisis desde la historia cultural», Revista de bistoriografía, 21 (2014): 191-207. 
ello. La antecámara constituía un lugar de gran importancia en el que compartían tiempos de espera los lacayos y sirvientes del monarca con los ministros, aristócratas y otras visitas. Era a la vez lugar ceremonial, pues tenía un sillón con dosel para las audiencias, y ámbito para la charla informal ${ }^{10}$. Más restringido era el acceso a la llamada «saleta» y a la «cámara del servicio personal de S.M.» ${ }^{11}$. Sin embargo, y en tanto que la monarquía se proyecta hacia el exterior por su carácter simbólico, no puede perderse de vista que el contexto de la sociabilidad puede ser también la calle, escenario primordial de la ceremonia barroca que el liberalismo utilizará con profusión, dándole un contenido distinto, pero siendo consciente de su capacidad para crear emoción colectiva al tratarse de un escenario más propicio a la difuminación de las diferencias de clase y de rango y a su disolución en un ideal superior: la nación, encarnada en el monarca ${ }^{12}$. Por lo que se refiere a los espacios de la sociabilidad informal, también los palacios reales fueron entornos propicios para estas actividades, así como el palco destinado al monarca y a su familia en el Teatro Real, lugar para ver y ser visto. Asimismo, se podrían mencionar los palacios de los aristócratas y burgueses enriquecidos, frecuentados por los reyes en bailes y otras actividades de ocio. En cualquier caso, hay que hacer notar la descentralización que, por lo que se refiere a los espacios del ocio cortesano, se produjo desde la muerte de Fernando VII y el inicio del régimen liberal, momento en que la aristocracia, «reducida entonces a la condición de servidora de Palacio» comenzará a abrir, también ella, sus salones ${ }^{13}$, compitiendo por el reconocimiento de la alcurnia, del lujo y de su capacidad de atracción de personajes influyentes (incluida la familia real) a sus fiestas.

Esto nos lleva a preguntarnos una cuestión: ¿dónde acaba lo que, técnicamente, consideraríamos «sociabilidad cortesana» y dónde empieza lo que denominamos «sociabilidad burguesa»? A este respecto hay que tener en cuenta que, a partir del reinado de Isabel II, el incremento en los nombramientos para cargos honoríficos de la corte fue muy notorio. Se trató de una política de acercamiento entre las viejas elites aristocráticas (poseedoras tradicionales de los cargos cortesanos) y aquellos individuos que habían alcanzado una posición relevante a raíz de los cambios económicos y sociales derivados del nuevo régimen. En algunos casos, esas políticas de fusión ya habían comenzado con anterioridad ${ }^{14}$. En otros, se producirían a lo largo del reinado de Isabel $\mathrm{II}^{15}$. Muchos banqueros, empresarios, industriales,

${ }^{10}$ Fernando Fernández de Córdova, Mis memorias intimas (Madrid: Sucesores de Rivadeneyra, 1889), III, 131.

11 Véase al respecto el Proyecto de Reglamento de Etiqueta Interior y Exterior del Real Palacio, Madrid, Imprenta Nacional, 1863 (Real Biblioteca, Caj.foll.fol.216).

12 Maurizio Ridolfi, «Las fiestas nacionales: religiones de la patria y rituales políticos en la Europa liberal del "largo siglo XIX"», Pasado y memoria, 3 (2004): 135-154.

${ }^{13}$ Ramón de Mesonero Romanos, Memorias de un setentón (Madrid: Editorial Castalia, 1994), 442. 2000).

${ }^{14}$ Jesús Cruz, Los notables de Madrid. Las bases sociales de la revolución liberal española (Madrid: Alianza,

15 Véase: Raquel Sánchez y David San Narciso, coords., La cuestión de Palacio. Corte y cortesanos en la España contemporánea (Granada: Comares, 2018). La nobleza en la España del siglo XIX: Germán Rueda, coord., La nobleza española, 1780-1930 (Madrid: Ediciones 19, 2014). 
políticos e, incluso, algunos hombres de letras y artistas accedieron a ese espacio virtual que es la corte a través de cargos de carácter meramente representativo, como algunas de las categorías de gentileshombres y de damas de la reina. De hecho, arribar a ese espacio constituía un signo de distinción entre los individuos situados en lo más alto de la escala social. Se trataba de los mismos nombres que se podían encontrar en otros centros de sociabilidad de la elite, como el ya citado Teatro Real o el Casino de Madrid ${ }^{16}$. Todo ello conduce a afirmar que, por lo que se refiere a las elites españolas, no puede hablarse de una frontera clara entre las prácticas asociadas a la sociabilidad cortesana y aristocrática y las relacionadas con la alta burguesía. No hay una disolución de la primera en la segunda. En ese contexto, en ambas clases sociales conviven y se entremezclan las mismas personas para negociar sus intereses económicos, políticos y matrimoniales.

Finalmente, podemos plantear la cuestión de si las prácticas de sociabilidad cortesana vienen más claramente definidas por la asistencia del rey o la reina a un determinado acto que por los espacios en que se desarrollan estas prácticas, pues la mera presencia del monarca obliga a la activación de los códigos de conducta cortesana marcados por el protocolo y la etiqueta, incluso en entornos y actividades sociales de carácter informal. Ciertamente, esto es así, pero hay que recordar que la corte no está constituía solo por el monarca: sin cortesanos no hay corte (como pudo amargamente comprobar el rey Amadeo), pero sin la presencia in situ del monarca sí la hay porque la clave explicativa de este colectivo social es justamente la existencia de cortesanos. Finalmente, la sociabilidad cortesana no solo se explica por la presencia del monarca en un evento, sino que la asistencia de otros miembros de la familia real también marcaba un signo de distinción en cualquier recepción o ceremonia.

\section{ISABEL II, ENTRE LA CEREMONIA Y LA FIESTA}

Durante el reinado de Fernando VII, la corte española reprodujo los rituales tradicionales de la majestad y la estrecha relación de la nobleza con el monarca como instrumento para reforzar el prestigio de este. Por lo tanto, las ceremonias y otros actos cortesanos tuvieron un papel muy significativo en un contexto, el reinado fernandino, en el que, tras los desafíos del liberalismo y las independencias americanas, la monarquía española iba a necesitar algo más que la legitimidad dinástica para sostenerse ${ }^{17}$. Sin embargo, la vida cortesana no solo era un espacio para el lucimiento de la nobleza y para la exhibición de su vínculo con el rey, sino que, como describió Fernández de Córdova en sus memorias, la sociabilidad cortesana informal, especialmente en los Reales Sitios, constituyó el vehículo natural para la

\footnotetext{
${ }_{16}$ Puede consultarse el trabajo de María Zozaya, El Casino de Madrid: ocio, sociabilidad, identidad y representación social (Madrid: UCM, 2008).

17 Véase Antonio Moral Roncal, iEl enemigo en Palacio! Afrancesados, liberales y carlistas en la Real Casa y Patrimonio (1814-1843) (Alcalá de Henares: Universidad de Alcalá, 2005): 39-46. Del mismo autor: «La Real Casa y Patrimonio en el reinado de Fernando VII (1814-1833)», en Raquel Sánchez y David San Narciso, coords., La cuestión de Palacio, 155-183.
} 
consecución de beneficios personales de todo tipo, teniendo siempre en cuenta la centralidad de la figura real como proveedora de favores y la necesidad de hacerse notar en tan competitivo entorno:

Claro está que a los Sitios Reales no iban las pretensiones subalternas; de modo que, entre aquel cúmulo de obispos y magistrados, generales y consejeros, oidores e intendentes, corregidores y covachuelistas, había siempre muchos que arrendaban y amueblaban con fastuosidad lindas casas, tomaban coches, vestían lacayos y desplegaban la pompa de los trajes o uniformes más vistosos. Ya he dicho que el favor de un ministro no bastaba entonces, como más tarde, para obtenerlo todo, y los aspirantes a altas posiciones, como necesitaban, más que de cosa alguna, de la privanza del Rey para conquistar poder, agotaban todos aquellos recursos que tenían para hacerse valer en los Sitios, en donde al mismo tiempo había mayores facilidades y ocasiones de acercarse a su Real persona ${ }^{18}$.

Los cambios comenzaron tras la muerte de Fernando VII cuando la reina regente, deseosa de rodearse de fieles, puso en marcha un programa de depuración del personal palatino con el objetivo de crear unos círculos cortesanos afines a ella y a su hija ${ }^{19}$. Mientras que las tropas isabelinas trataban de asegurar el trono de la reina niña en el campo de batalla, María Cristina se sirvió de las prácticas de ocio para estrechar lazos con las elites liberales afines, principales soportes de su hija. Para ello comenzó a frecuentar los salones privados de aristócratas y políticos liberales de renombre, como evidencian las visitas que realizaba a los bailes organizados por el conde de Toreno. Fernández de Córdova hizo notar la novedad de este hecho al escribir que era «la primera vez que se vio en España a un soberano realzando con su presencia la casa de un particular» ${ }^{20}$. Esta circunstancia marcaba un hito en la relación de la Corona con sus súbditos más privilegiados, pues si bien el monarca seguía siendo el centro de la sociabilidad cortesana, se diversificaron los escenarios en que sus apariciones públicas tenían lugar. Palacio, por supuesto, continuaba siendo el ámbito primordial de las relaciones entre los cortesanos, pero las posibilidades que ofrecían las diversas manifestaciones de sociabilidad informal iban a convertirse en el lazo de unión de esas elites.

Durante la regencia del general Espartero, el distinto concepto que sobre la monarquía sostenía la cultura política progresista, unido al rechazo que generó en la aristocracia el exilio de la reina madre, restó preponderancia al rol simbólico de la vida cortesana en la sociedad española. A pesar de que eran titulares de puestos importantes en la servidumbre real, señalaba la condesa de Espoz y Mina que, después del asalto a Palacio Real en octubre de 1841 por parte de los generales Concha, León y Pezuela, los grandes de España y el resto de la aristocracia ni siquiera

\footnotetext{
${ }^{18}$ Fernando Fernández de Córdova, Mis memorias intimas, I, 68. Una descripción de la vida cortesana desde el matrimonio de Fernando VII con María Cristina de Borbón en R. Mesonero Romanos, Memorias de un setentón, 437-448.

${ }^{19}$ Véase el capítulo VI de Antonio Moral Roncal, ;El enemigo en Palacio!

${ }^{20}$ Fernando Fernández de Córdova, Mis memorias intimas, I, 190.
} 
se molestaron en visitar a la reina niña y a su hermana para conocer su estado ${ }^{21}$. De esta forma trataban de mostrar su rechazo a la decisión del regente Espartero de fusilar a uno de los suyos: el general Diego de León. Esta actitud, así como el incumplimiento de sus obligaciones palaciegas, eran una toma de postura política muy clara en la cual evidenciaban su fidelidad no a la Corona, sino a la persona de la reina regente. Sin embargo, tras la mayoría de edad de Isabel II, y con el deseo de potenciar el papel de la Corona, el Palacio Real se convirtió de nuevo en el motor de la actividad social. Según varios contemporáneos, fue precisamente la reina madre, María Cristina, quien impulsó la celebración de una gran variedad de recepciones y bailes con el objetivo de rodear a la Corona del brillo que, en su opinión, debía tener la principal institución del país ${ }^{22}$. Uno de estos contemporáneos fue el escritor norteamericano Washington Irving, quien entre 1842 y 1846 desempeñó los cargos de enviado extraordinario y ministro plenipotenciario de los Estados Unidos en España. Irving, que ya había visitado España en los últimos años del reinado de Fernando VII, escribió varias cartas a su familia en las que narraba el significativo cambio que se había producido en la corte española desde que la reina madre llegó de su exilio parisino en 1844. Incidía Irving en la forma en la que la vida social impulsada por Palacio había transformado y estrechado las relaciones entre la alta sociedad y la Corona, convirtiendo a esta en el núcleo aglutinador de las clases privilegiadas y revalidando así su liderazgo, por una parte, en la jefatura del Estado y, por otra, entre las elites aristocráticas de viejo y de nuevo cuño ${ }^{23}$. En la misma línea se pronunciaron el ya citado Fernando Fernández de Córdova y Alfredo Escobar, marqués de Valdeiglesias quien, en sus memorias, recuerda reiteradamente que la corte de Isabel II fue una de las más brillantes de la Europa de su tiempo ${ }^{24}$.

Durante el reinado de Isabel II, y precisamente en ese contexto de revalorización del papel social y político de la Corona, los rituales y ceremonias de la monarquía alcanzaron una dimensión performativa muy importante. Aunque en líneas generales se mantuvo la liturgia tradicional, resultaba evidente que, de una forma o de otra, deberían producirse cambios en algunas de estas ceremonias para adaptarse a los requerimientos de una monarquía constitucional, sobre todo en aquellas con un alto contenido político. Un análisis meramente superficial de estas ceremonias nos muestra la tensión existente entre la Corona y los representantes de los poderes legislativo y ejecutivo acerca de la presencia de estos últimos en las mismas, como veremos en el ejemplo de las ceremonias asociadas al nacimiento del

${ }^{21}$ Condesa de Espoz y Mina, Memorias (Madrid: Tebas, 1977): 252.

${ }^{22} \mathrm{La}$ importancia del baile como práctica social en Guadalupe Mera, El baile en el Madrid romántico (1833-1868): prácticas de sociabilidad, repertorio coreográfico y recepción literaria (Oviedo: Universidad de Oviedo, 2015).

${ }^{23}$ Salvador García Castañeda, «Ecos de sociedad: la vida cortesana isabelina (1842-1846) que vio Washington Irving», en Dolores Thion, coord., El costumbrismo, nuevas luces (Pau: Presses de l'Université de Pau, 2013): 233-250.

${ }^{24}$ Marqués de Valdeiglesias, Setenta años de periodismo. Memorias (Madrid: Biblioteca Nueva, 1950): I, passim. 
príncipe de Asturias ${ }^{25}$. Los actos puramente cortesanos más frecuentes en el reinado de Isabel II fueron la toma de la almohada, la cobertura de los grandes, los besamanos y la muy antigua ceremonia del lavatorio de los pies. En la celebración de esta última, que se oficiaba en la Sala de los Pilares de Palacio en Jueves Santo, y como nos cuenta una testigo contemporánea, se evidenciaron a mediados de siglo las dificultades de adaptación de la etiqueta tradicional a las novedades sociales y políticas con la inclusión entre los participantes de las esposas de los ministros y de los representantes diplomáticos ${ }^{26}$.

Las ceremonias de bautismo y presentación del heredero nos ofrecen otro ejemplo de la sociabilidad ceremonial que hemos descrito páginas atrás. A estas ceremonias les siguió el viaje que realizó la familia real a Asturias, a Covadonga, con un claro interés político al tratar de unir al príncipe Alfonso con don Pelayo y, por tanto, con el origen histórico de España ${ }^{27}$. Nos encontramos ante un proceso ceremonial en cuatro secuencias, un ritual con una interpretación política muy significativa en un momento de quiebra en la popularidad no solo de la reina, sino del propio sistema nacido tras la muerte de Fernando VII. Se trata de cuatro episodios, fechados entre noviembre de 1857 y el verano de 1858, que comienzan con el bautismo, continúan con la ceremonia de presentación y cruzamiento del heredero por parte del rey consorte, siguen con la presentación del niño a la Virgen de Atocha y, finalizan con el citado viaje a Asturias. Si nos centramos en lo que aquí nos interesa, las prácticas sociales asociadas a esta ceremonia, nos encontramos con que hay una progresión -por lo que se refiere a la implicación de distintos colectivos sociales en la misma- que tiene una relación directa con la amplitud de los espacios en los que se desarrollan las fases de este ritual y con los públicos que las presenciaron.

La ceremonia, en su primera estación, el bautismo del príncipe Alfonso, se desarrolló a través de las galerías de Palacio hasta llegar a la Capilla Real, es decir, en un lugar reducido y para un grupo restringido de individuos: el arzobispo de Toledo y los dieciocho obispos que le asistieron en el bautismo, monseñor Lorenzo Barili (el

${ }^{25}$ Un ejemplo de esta tensión entre las instituciones representativas del Estado y la Corona nos lo proporciona Javier Varela al señalar que solo a partir del entierro del infante Francisco de Paula en 1865 se permitió la presencia de representantes del gobierno, las Cortes y los tribunales, es decir, de los tres poderes del Estado, en el traslado al monasterio de El Escorial y en la inhumación de los miembros de la familia real. De hecho, con motivo de la muerte de Alfonso XII, la prensa demandó que «a la vieja etiqueta de los reyes absolutos, sustituya la etiqueta de los reyes constitucionales» (Javier Varela, La muerte del rey: el ceremonial funerario de la monarquía española, 1500-1885, Madrid: Turner, 1990: 74).

${ }^{26}$ Frances Calderón de la Barca, Un diplomático en Madrid. Impresiones sobre la corte de Isabel II y la revolución de 1854 (Zaragoza: Institución Fernando el Católico, 2018): 244-245. Hace referencia la autora a la carencia de información acerca de la indumentaria que debían llevar estas señoras a la ceremonia del lavatorio y la confusión que ello creó en el cuerpo diplomático. La ceremonia concluía siempre con una comida, servida por los propios monarcas, para los doce pobres a los que se había lavado los pies previamente.

${ }^{27}$ Se sigue aquí el trabajo de David San Narciso Martín, «Celebrar el futuro, venerar la Monarquía. El nacimiento del heredero y el punto de fuga ceremonial de la monarquía isabelina (1857-1858)», Hispania, 77/255 (2017): 185-215. 
nuncio papal, que representaba a Pío IX como padrino del niño), los gentileshombres y mayordomos de Palacio, la familia real, las damas de la reina, los grandes de España y, cerrando la comitiva, el general Evaristo San Miguel como comandante de los alabarderos. Todo ello pautado según la vieja tradición de la monarquía, de ahí que tuvieran que anularse las invitaciones que los organismos oficiales enviaron a diversos particulares que iban a asistir representando a varias instituciones del Estado. La razón que se arguyó fue que se trataba de un acto privado, excusa sorprendente tratándose del bautismo del heredero al trono de una de las monarquías más antiguas de Europa. La segunda parte fue la llamada ceremonia del cruzamiento, por la que el rey consorte Francisco de Asís, previa autorización de la reina, impuso al niño el Toisón de Oro y las cruces de las órdenes de Carlos III e Isabel la Católica. En esta segunda parte se incrementó el número de participantes, incluyéndose ahora a otros cargos palaciegos, entre los que había viejos y nuevos títulos nobiliarios. La participación de todos estos individuos en dichas ceremonias, las más protocolarias de todo el ritual, tenía como objeto sellar la vinculación del nuevo príncipe con sus pares, aquellos que se considerarían en un futuro sus más ardientes defensores y a los que se encontrarían, tanto él como el resto de la familia real, en otro tipo de actos semejantes. Para los invitados, participar en eventos como estos, extremadamente elitistas, era un signo de distinción que les significaba en la alta sociedad de la época. La tercera secuencia de la ceremonia fue la presentación del niño en la basílica de Atocha de Madrid. De nuevo aquí volvemos a ver a las elites nobiliarias en sus carruajes acompañando a la familia real, así como a palafreneros y tropas de escolta, pero se introduce un nuevo elemento en el cortejo: el público, que participa en la celebración desde la calle, aclamando a la comitiva y, en especial, al heredero. Como dejó escrito el marqués de Vinent, en la ceremonia participaron «las gentes en dos categorías: los llamados a desfilar y los llamados a ver desfilar» ${ }^{28}$. De hecho, los festejos populares organizados se hallaban claramente disociados de las ceremonias. En estas últimas, el protocolo marcaba las distancias entre las clases sociales, impidiendo su mezcla. Las fiestas populares, por su parte, estaban destinadas para el disfrute de las clases media y baja, sin participación de individuos mejor situados en la escala social. Finalmente, en la última secuencia de la ceremonia, el viaje a Asturias, se amplían los colectivos sociales participantes pues, además de la comitiva real, con un elevado número de cortesanos, aristócratas y miembros del gobierno, se quiso hacer partícipe del acto al pueblo español, no solo en sentido social, sino también territorialmente hablando, con paradas en diversas localidades del recorrido. Evidentemente, la participación popular en los actos con la familia real y los cortesanos era siempre pasiva, contemplativa. Sin embargo, el mero hecho de compartir la emoción colectiva por el nacimiento del príncipe heredero en un acto festivo, aunque fuera por breves instantes, contribuía a que la gente común

\footnotetext{
28 Antonio de Hoyos, El primer estado. Actuación de la aristocracia antes de la revolución, en la revolución y después de ella (Madrid: Rh+, 2013): 35.
} 
se sintiese miembro de esa colectividad llamada «nación española» ${ }^{29}$. El sentido político de estas recepciones asociadas a la sociabilidad ceremonial es más que evidente y constituye un ejemplo muy claro de las manifestaciones de la «monarquía escénica».

También al analizar la sociabilidad lúdica o informal vinculada al mundo cortesano hay que hacer mención a los comentarios realizados más arriba acerca del papel de la Corona como agente activador, como aglutinante de unas elites sociales híbridas en relación a su origen, aunque bastante asimilables por lo que respecta a su nivel económico. El dinero constituía, en última instancia, el pegamento social que permitió la renovación de la alta sociedad en los tiempos de Isabel II. En su estudio sobre estos entornos, Cristina del Prado explica cómo la denominada «estación mundana» se iniciaba en los salones del Palacio Real que, de esta forma, daban el pistoletazo de salida para la apertura de los salones de las clases altas ${ }^{30}$. El calendario comenzaba en octubre y alcanzaba su máximo nivel entre el carnaval y la Semana Santa, momento en que se suspendían las fiestas para retomarse después del domingo de Pascua. La temporada quedaba clausurada en junio, cuando tanto la familia real, como los cortesanos y las clases altas se marchaban de veraneo a distintos destinos. Isabel II inauguró la costumbre de recibir una vez por semana, costumbre imitada por los salones de las elites, de tal forma que una persona de este nivel social y bien relacionada podía asistir a distintas recepciones (bailes, veladas, cenas, etc.) todos los días de la semana, visitando varios salones en una misma noche. La reina, en su doble condición de monarca y de esposa del matrimonio de más alto rango de la sociedad española, se convertía en anfitriona de sus súbditos más distinguidos, patrón que reproducirán las esposas e hijas de los aristócratas, diplomáticos, banqueros y empresarios de la época, las cuales, retomando el papel civilizador atribuido a las mujeres en las reuniones sociales del siglo XVIII, se convertirían en las organizadoras y animadoras de este tipo de recepciones.

El efecto imitador de las prácticas de sociabilidad cortesana de carácter lúdico no se extendía solo al hecho de tomar por costumbre la celebración de un acto social determinado día de la semana, sino que las elites también reproducían la tipología de actos que se celebraban en Palacio. Hay que hacer aquí algunas matizaciones pues, precisamente porque los entornos de sociabilidad ligados a la corte eran ámbitos especiales, en ellos tenían lugar algunas actividades que mezclaban lo ceremonial con lo lúdico, como las recepciones que tenían lugar antes o después de los besamanos, o las fiestas en honor de algún personaje público, homenajeado por los reyes ${ }^{31}$. Por lo que respecta al resto de actos sociales, tanto en Palacio como en los Reales Sitios, se desplegaba un amplio panorama de actividades que iban desde los bailes hasta las

\footnotetext{
${ }^{29}$ Sobre el papel nacionalizador de la monarquía en este periodo: Raquel Sánchez, coord., Hacia una monarquia nacional: la Corona como agente de nacionalización en España (1833-1885), Hispania, LXXIX/262 (2019); y Raquel Sánchez, ed., Un rey para el pueblo. Monarquia y nacionalización en el siglo XIX (Madrid: Sílex, 2019).

${ }^{30}$ Cristina del Prado, El todo Madrid, p. 79.

${ }^{31}$ Como por ejemplo la fiesta en honor de los generales recién llegados de la guerra de África en 1860, que se celebró en Aranjuez el 6 de mayo de 1860 (Cristina del Prado, El todo Madrid, p. 80).
} 
comidas y cenas, pasando por las veladas musicales y teatrales. En Palacio Real había un teatro en el que, en ocasiones, la reina salía a cantar. La popularidad de los teatros caseros fue tal, como nos cuenta Valdeiglesias, que durante los últimos años del reinado de Isabel II se generalizaron no solo en los palacetes aristocráticos y de la alta burguesía, sino también en las más modestas casas de la clase media, convirtiéndose la lectura y la representación de obras teatrales en un pasatiempo muy habitual en la época ${ }^{32}$. Por otra parte, fueron relativamente frecuentes las celebraciones de los cumpleaños o santos de miembros de la familia real, que se sustanciaban en comidas de etiqueta, así como las celebraciones navideñas.

Ser invitado a alguna de estas recepciones cortesanas constituía un signo de especial distinción para el individuo agraciado pues no solo le permitía acceder al entorno de sociabilidad más prestigioso de la elite, sino que le abría las puertas al establecimiento de contactos y relaciones que podían ser muy productivas para su promoción personal. Los actos informales, libres de las ataduras protocolarias (a pesar de que, en mayor o menor medida, siempre se hallaban presentes en el entorno real), permitían una mayor fluidez en las relaciones personales y facilitaban el camino para ser aceptado en el llamado «todo Madrid», lo que significaba que la persona en cuestión podía acceder también a los salones de otros individuos de las clases altas. En ocasiones, el camino era el contrario: desde los salones de la aristocracia se accedía a los salones reales. En cualquier caso, el resultado era el mismo: ingresar en la elite, consiguiendo de ese modo un capital simbólico que prestigiaba al individuo y a su familia. A su vez, estos parvenus, si realmente pretendían convertirse en personajes de referencia en el ámbito mundano, debían actuar como anfitriones, lo que implicaba grandes gastos de ostentación que no todos se podían permitir ${ }^{33}$. Los casos de los banqueros Salamanca y Gaviria son un ejemplo claro de ascenso social vinculado a estas prácticas.

Por otra parte, y al igual que había hecho su madre en los primeros años del régimen liberal, la reina Isabel asistió con frecuencia a los bailes de la elite aristocrática y burguesa. Su presencia en estas reuniones sociales también constituía un elemento de distinción para la familia anfitriona y un interés añadido para los demás invitados. Sin lugar a dudas, la asistencia de la reina a una recepción de estas características alteraba la normal conducta de los concurrentes al convertirse en el principal centro de atención y al condicionar, con su vestimenta, sus gustos y su conducta el desarrollo de la misma. Sin embargo, contribuía a sellar la alianza entre la Corona y las elites, un pacto que afianzaba la solidaridad entre los miembros de la aristocracia. Esto fue especialmente importante a medida que la popularidad de la reina fue descendiendo y necesitó de apoyos en sus tradicionales soportes, los cuales se hallaban ligados a ella tanto por su vinculación a la corte por ser cargos palatinos y/o por amistad personal. Durante su juventud, en especial después de su mayoría de

\footnotetext{
32 Marqués de Valdeiglesias, Setenta años de periodismo, vol. 1, pp. 47-48. Valdeiglesias menciona los teatros de los barones de Andilla, y los de las condesas de Montijo y de Vilches, muy aficionada esta última a la actuación.

${ }^{33}$ Un ejemplo de lo que tales gastos suponían para las familias en Frances Calderón de la Barca, Un diplomático en Madrid, p. 68.
} 
edad y su matrimonio, Isabel II llevó una agitada vida social, asistiendo a un gran número de bailes y recepciones, lo que contribuyó a proyectar sobre ella una cierta fama de frivolidad que perjudicó seriamente su reputación, al sobrepasar con su conducta los límites del estereotipo de la domesticidad burguesa que comenzaba a imponerse también en la imagen pública de las reinas ${ }^{34}$.

\section{LA CORTE OFICIOSA DE LA REINA MARÍA CRISTINA}

La mayoría de edad de Isabel II no restó protagonismo a su madre en el mundo social de su tiempo. Aceptado públicamente su matrimonio con Fernando Muñoz, la familia que formó con éste constituyó el otro gran polo de atracción cortesano de la época. Si bien la exregente no se hallaba en disposición de otorgar cargos honoríficos que abrieran la puerta de Palacio (al menos, no personalmente), entre los años 1844 y 1854 se convirtió en el centro de lo que se podría calificar como una corte «paralela» $\mathrm{u}$ «oficiosa», formada por los mismos individuos que frecuentaban la corte «oficial» y los salones de la aristocracia y la alta burguesía ${ }^{35}$. La diferencia estribaba en que los salones de María Cristina no se llevaban a cabo ceremonias de estado, por lo que los encuentros lúdicos constituían una oportunidad excepcional para el establecimiento de relaciones de todo tipo. A la vez, la presencia de la reina madre y de sus hijos rodeaba a las recepciones del «halo fascinante» de la monarquía. De este modo, el Palacio de las Rejas, residencia de la familia MuñozBorbón, constituía un espacio privilegiado para la sociabilidad informal de las elites, un espacio plástico en el que los invitados circulaban y se movían libremente sin las restricciones protocolarias de Palacio Real y los Reales Sitios. Frances Calderón de la Barca contaba en su libro que el tipo de actividades que se organizaban en el Palacio de las Rejas era más variado que las que se podían encontrar en el Palacio Real: desde pequeñas recepciones y veladas hasta bailes de gala, pasando por los muy populares bailes de trajes (disfraces) o los bailes de máscaras, igualmente populares. Como comentaba Fernández de Córdova en sus memorias, las máscaras, prohibidas en tiempos de Fernando VII por razones policiales, se convirtieron en uno de los pasatiempos más extendidos en la época isabelina porque permitían el juego de equívocos que los roles de clase y género tenían vedado en otras circunstancias ${ }^{36}$.

Las fiestas de María Cristina reunían, además, a una mayor variedad de personas, pues a ellas asistían aristócratas, políticos, ministros, empresarios, militares,

34 Véase Mónica Burguera, «“Al ángel regio”. Respetabilidad femenina y monarquía constitucional en la España posrevolucionaria», en Encarna García Monerris, Mónica Moreno y Juan I. Marcuello, coords., Culturas politicas monárquicas en la España liberal (Valencia: Universitat de València, 2013): 131150 .

${ }_{35} \mathrm{M}^{\mathrm{a}}$ Ángeles Casado, «María Cristina de Borbón. Una regente cuestionada», en Emilio La Parra, coord., La imagen del poder. Reyes y regentes en la España del siglo XIX (Madrid: Síntesis, 2011): 133-176. Un análisis de la vida social en su palacete madrileño en Raquel Sánchez y David San Narciso, «Fiesta en Palacio, revolución en la calle, estudio introductorio a Un diplomático en Madrid (1853-1854)», en Frances Calderón de la Barca, Un diplomático en Madrid, LII-LX.

${ }^{36}$ Fernando Fernández de Córdova, Mis memorias intimas, II, 175. 
banqueros, grandes propietarios, hombres de letras y artistas. Frecuentaban sus salones en especial los individuos vinculados al moderantismo, con los que la exregente tenía unas relaciones especialmente próximas. Calderón de la Barca nos da algunos nombres: Luis Sartorius, los duques de Frías y Fernandina, el marqués de Viluma, José Castro y Orozco, Mariano Roca de Togores, José Buschental, Agustín Esteban Collantes, Félix Domenech, el general Blaser, el vizconde del Pontón, los marqueses de Biario Sforza, Villadarias, de la Unión, Santa Cruz, Rivas, Medinaceli, los duques de Alba, José de Salamanca y un largo etcétera. Una invitada especialmente destacada para lo que aquí nos interesa es la propia reina Isabel, que frecuentaba las recepciones de su madre asiduamente. Isabel, muy aficionada al baile y a la música, podía dar rienda suelta a su natural espontaneidad en estas reuniones en las que ella no era la anfitriona y en las que las rigideces protocolarias se hallaban ausentes. Frances Calderón nos describe también, es difícil saber si voluntaria o involuntariamente, la diferencia de comportamiento entre madre e hija en los bailes del Palacio de las Rejas. Esta última, alegre y expansiva, contrasta con su madre, quien nunca perdía su condición de reina, su aire majestuoso, incluso en momentos en que la frivolidad imperaba. María Cristina, según la visión que nos proporciona Frances Calderón, sin ser distante, sabía otorgar a los actos en los que participaba de un aura de brillo y majestad que a la vez combinaba con una controlada y amable simpatía que hacía sentirse cómodos en su presencia a los asistentes. La forma en la que se describe el inicio de uno de sus bailes nos puede dar una idea de lo que aquí se viene diciendo:

Muy pocos bailes comienzan a animarse antes de la una. Los de la reina Cristina son una excepción en este punto. A las diez entró Su Majestad, seguida de sus tres hijas y sus ayas; pero fueron pocos los invitados que llegaron antes de las once, excepción hecha de los ministros de la Corona y sus familias. Ellos, los gentileshombres y damas de Palacio, y unos cuantos grandes que, a lo que tengo entendido, son invitados por turno, constituían la reunión. En total habría allí unas ciento cincuenta personas. La reina madre tiene, como la condesa de Montijo, el don de inspirar confianza a cuantos se le acercan. Sus invitados se sienten en su casa como si estuvieran en las suyas propias. / Estaba la reina sentada a un lado de la sala, muy lujosamente vestida y con mucho gusto. Las infantas Amalia y Cristina, con sus ayas, estaban a su derecha; el infante don Francisco, con su hijo, a la izquierda. Las tres hijas de la reina Cristina, que son muchachas encantadoras, eran, por supuesto, los personajes principales de la reunión. El duque de Riánsares, que es todavía un hombre de hermosa presencia, aunque muy calvo, se quedó en la entrada recibiendo muy cordialmente a sus huéspedes ${ }^{37}$.

Por otra parte, y al igual que hizo en los años en que ejerció como reina regente, María Cristina asistió a bailes y recepciones en casas de particulares. Liberada ya de sus compromisos oficiales, la exregente frecuentó los domicilios de políticos y empresarios afines a ella. Conocida es su relación con Manuel Gaviria, su banquero,

\footnotetext{
${ }^{37}$ Frances Calderón de la Barca, Un diplomático en Madrid, 206.
} 
cuyo palacio en la calle del Arenal de Madrid visitó en varias ocasiones. Como se acaba de señalar, el círculo más próximo a María Cristina estaba formado por un grupo de personas en el que se mezclaban los cortesanos con la burguesía enriquecida y algunos políticos moderados, formando una red que controló buena parte de los negocios de la España de la época. Compartiendo todos ellos los mismos intereses económicos y políticos, constituyeron un grupo de presión que alcanzó una gran influencia y que, gracias al amparo de la regente, consiguió pingües beneficios de los contratos de obras públicas, muchos de ellos gestionados en las reuniones sociales que aquí se vienen mencionando. En estos y otros negocios la propia regente y su marido tuvieron un papel importantísimo, siendo ellos la cabeza de ese grupo de presión que, para la opinión pública, representaba el ejemplo más claro de la corrupción imperante durante los primeros años del reinado efectivo de Isabel II. Ahí se halla la razón que explica la furia del ataque popular contra el Palacio de las Rejas en 1854, símbolo de todo ese mundo de inmoralidad recubierto por el oropel de los bailes de gala ${ }^{38}$.

\section{UN REY SIN CORTE: AMADEO I}

Con Amadeo de Saboya nos encontramos ante dos realidades de importancia que nos van a permitir comprender la escasa actividad social habida en la corte durante su breve reinado. Por una parte, el rey llegó a España con un concepto muy distinto de lo que debía ser y representar un monarca ${ }^{39}$. Teniendo en cuenta, además, que el origen de su legitimidad como rey difería bastante del de su predecesora, a Amadeo no le cabía más opción que presentarse ante sus súbditos como un monarca austero, próximo a los ciudadanos, con una planta palatina acorde a los requerimientos de una monarquía democrática, es decir, más simple y manejable que la borbónica ${ }^{40}$. Por otra parte, el rechazo que las elites isabelinas mostraron desde un primer momento a la pareja real impidió que se pudiera revivir la ajetreada vida cortesana del reinado anterior. El vacío que la aristocracia, de nuevo y viejo cuño, hizo a Amadeo y a su esposa la reina María Victoria es una prueba fehaciente de la fortaleza de los lazos estrechados en las reuniones sociales celebradas en los años anteriores y del éxito de la política, más o menos consciente, de servirse de los actos de sociabilidad formal e informal como instrumentos de revalidación de la dinastía reinante $^{41}$. Si hemos visto que en aquella época las prácticas sociales de la corte y su

\footnotetext{
38 Isabel Burdiel, Isabel II (Madrid: Taurus, 2010): 216-222; y Juan Pro, «Poder político y poder económico en el Madrid de los moderados (1844-1854)», Ayer, 66 (2007): 27-55.

39 Véase: Alicia Mira Abad, «La imagen de la Monarquía o cómo hacerla presente entre sus súbditos: Amadeo y María Victoria», Mélanges de la Casa de Velázquez, 37/2 (2007): 173-198.

${ }^{40}$ Véase al respecto: Carmen Bolaños Mejías: «La casa real de Amadeo I de Saboya: rasgos organizativos», en María Dolores del Mar Sánchez González, coord.: Corte y monarquía en España (Madrid: Ed. Centro de Estudios Ramón Areces, 2003): 259-300; e Isabel María Pascual Sastre, «La corte bajo una constitución democrática. La Casa Real en el reinado de Amadeo I», en Raquel Sánchez y David San Narciso, coords., La cuestión de Palacio, 263-299.

${ }^{41}$ Raquel Sánchez, «Política de gestos. La aristocracia contra la monarquía democrática de Amadeo», Pasado y memoria, 18 (2019): 19-38.
} 
entorno pueden servirnos como herramientas para comprender las relaciones entre los sectores más privilegiados, sus formas de promoción personal y sus actividades económicas y políticas, durante el reinado de Amadeo I el análisis de vida social de los círculos próximos al rey nos permite conocer hasta qué punto participar en los actos sociales de la corte se había convertido en un elemento que significaba políticamente a los individuos. Más aún, asistir a los eventos organizados por los aristócratas o grandes burgueses claramente opuestos al matrimonio real constituía también una toma de posición política que situaba a las personas en una oposición sorda y constante a la nueva dinastía. Los reyes, de hecho, no fueron jamás invitados a ninguna de las fiestas de la alta sociedad ${ }^{42}$. Además, los salones aristocráticos acabaron siendo centros de conspiración activa en contra de los Saboya, como tan claramente reflejaron las novelas de Pérez Galdós y del padre Luis Coloma. Tampoco los militares isabelinos aceptaron al nuevo rey, pues un buen número de ellos se negó a jurarle fidelidad, tal y como exigían la circular de 24 de enero de 1871 y la real orden de 6 de febrero de $1871^{43}$.

Dadas estas circunstancias, no es de extrañar que desde un primer momento el rey Amadeo tuviera muchas dificultades para formar la servidumbre de su casa ${ }^{44}$. Para los puestos de mayordomo y caballerizo mayor se designó al duque de Tetuán, Carlos Manuel O'Donnell, sobrino y heredero de los títulos del por entonces fallecido general O’Donnell, que renunciaría al poco tiempo. Las mismas dificultades surgieron para el nombramiento de las damas de la reina María Victoria. La duquesa de la Torre (esposa de Serrano) y la viuda de Prim rechazaron el cargo de camarera mayor, la última, al parecer, por su reciente viudedad. De hecho, el conde de Romanones, en su biografía del rey, cuenta hasta qué punto era escasa la corte real que, en su retiro veraniego en La Granja, la reina María Victoria solo tenía una dama que le hiciera compañía ${ }^{45}$. Para tratar de crearse un círculo afín, el rey Amadeo concedió títulos nobiliarios a sus partidarios, entre los cuales se encontraban una buena parte de los revolucionarios más moderados. Sin embargo, la idea de rodearse de una aristocracia, que parecía comprensible, preocupaba a algunos de sus simpatizantes, quienes sospechaban de las intenciones de los oportunistas que se acercaban al rey ${ }^{46}$. Los representantes británico y norteamericano trataron de tender puentes, sin gran éxito, entre la alta sociedad isabelina y la exigua corte de simpatizantes de Amadeo. La celebración de algunas fiestas en sus respectivas

\footnotetext{
42 Cristina del Prado, El todo Madrid, 43.

43 Gaceta de Madrid, 7.2.1871.

${ }^{44}$ Referencia del conde de Romanones, Amadeo de Saboya. El rey efimero (Madrid: Espasa Calpe, 1935): 73-74.

${ }^{45}$ Conde de Romanones, Amadeo de Saboya, 92.

46 Ildefonso Bermejo, La Estafeta de Palacio (Historia del último reinado). Cartas trascendentales dirigidas al Rey Amadeo, (Madrid: Imprenta de R. Labajos, 1871): I, 123-124. Más información sobre los títulos otorgados por Amadeo en José Francisco Olmos y David Ramírez Jiménez, Los títulos nobiliarios durante el Sexenio Revolucionario (1868-1874) (Madrid: Real Academia Matritense de Heráldica y Genealogía, 2017).
} 
legaciones apenas consiguió los frutos deseados ${ }^{47}$. Pese a todo, fue precisamente la llegada de nuevos diplomáticos a España la oportunidad más conveniente, por su aparente neutralidad, para la organización de recepciones en Palacio, como la que se celebró para homenajear al representante austríaco en febrero de 1872. Los nombres que más aparecen en las celebraciones datadas por Cristina del Prado, nombres que no siempre se repiten en los pocos actos que tuvieron lugar durante el reinado, son los de la condesa de Almina (hija del general Ros de Olano y dama de compañía de la reina María Victoria), los marqueses de San Rafael, del Duero y de La Habana, los generales Gándara y Zavala, las duquesas de Tetuán, de la Torre, de Veragua e incluso el duque de Fernán Núñez quien, a pesar de proceder de una familia fiel a la exreina, era amigo íntimo de Amadeo de Saboya. En esta lista hay que incluir también a los servidores italianos que habían llegado con el rey desde su país y, en especial, al marqués de Dragonetti y al conde de Locatelli, así como a políticos y escritores como Cristino Martos, Manuel Ruiz Zorrilla, Antonio Ferrer del Río, Gaspar Núñez de Arce o Juan Valera.

Como se indicaba más arriba, uno de los grandes problemas del rey Amadeo para crear un ambiente cortesano derivaba de su concepción de la monarquía. La idea de un rey próximo y austero podía atraer a sus súbditos más racionales y concienciados políticamente. Sin embargo, este paradigma del rey democrático se hallaba muy lejos de la cosmovisión tradicional del pueblo español y de sus elites, acostumbrados al lujo y al boato proyectado por las fiestas y las ceremonias borbónicas. Las descripciones que de aquellos eventos nos han dejado la prensa y la producción memorialística de los contemporáneos están plagadas de alusiones a la suntuosidad de las vestimentas, al brillo de las joyas, a la belleza de las mujeres, a la gallardía de los varones, al esplendor de la decoración de los salones... Probablemente, todos esos ditirambos no fueran más que meras exageraciones, pero cumplieron su función al rodear al mundo cortesano de una aureola de magnificencia que a la vez que marcaba las distancias con la gente común, reforzaba el vínculo entre monarca y súbditos. De este modo, la monarquía lograba así transmutarse en el símbolo de la nación, la cual veía en el brillo que rodeaba al monarca y a su corte el reflejo de su propia grandeza como pueblo. Frente a esto, con Amadeo reinaba en Palacio «una atmósfera de economía burguesa», como decía el marqués de Lema, quien nos ha dejado un muy elocuente testimonio de la sencilla presentación del tercer hijo de la pareja real al gobierno, niño que, al fin y al cabo, era un infante de España:

Al nacer un hijo de los reyes [Luis Amadeo], el Gobierno acudió de uniforme e hiciéronse las citaciones que prescribía el protocolo tradicional y ¡cuál fue la sorpresa al ver salir al Rey en una cámara casi en tinieblas y expresarles que, siendo aquel acontecimiento puramente privado, no entendía procedentes ceremonias molestas

\footnotetext{
${ }^{47}$ Cristina del Prado, «Los salones de la nobleza española durante el reinado de Amadeo I», Aportes, 91 (2016): 27-56. La labor mediadora de los diplomáticos fue incluso anterior a la llegada del rey (Valdeiglesias, Setenta años de periodismo, I, 93).
} 
con asistencia de altos dignatarios del Estado! Al fin, aunque con escaso relieve, hízose ante ellos la presentación del regio vástago ${ }^{48}$.

\section{CONCLUSIÓN}

La vida y las prácticas cortesanas supusieron para la monarquía un elemento muy importante a la hora de reforzar su poder simbólico. La Corona, a través de la sociabilidad ceremonial y de la sociabilidad lúdica, consiguió reformular su papel público adquiriendo un significado simbólico como representación de la nación que, si bien no se correspondía con su verdadero poder efectivo, mostraba el esplendor de la corte como una metáfora de la grandeza nacional. Los dos principales modelos de monarquía que se sucedieron en España antes de la Restauración, el borbónico y el amadeísta (el caso carlista merecería un tratamiento aparte) se correspondieron también con un modelo cortesano distinto. La corte isabelina, fastuosa y brillante, mostraba un estilo de monarquía que, si bien tenía muchas deudas con tiempos pasados, se integró perfectamente en el sistema político elitista y censitario construido a partir de 1845, con unas jerarquías sociales marcadas por el dinero y el título nobiliario. Otra cuestión a tratar es hasta qué punto a esa corte cabe achacarle responsabilidades en la gestión política que la reina hizo de las problemáticas que le competían. El modelo cortesano amadeísta, más sobrio y casi, podríamos decir, republicano en sus valores, era el reflejo de un sistema político democrático y más abierto políticamente. Es bien cierto que la monarquía saboyana no cayó solamente por la falta de apoyo de las clases altas. Sin embargo, no es nada desdeñable plantearse hasta qué punto fue importante, para su falta de arraigo, la inexistencia de un entorno cortesano que hubiera rodeado a la familia real del brillo que la mayoría de sus súbditos, insertos en una cosmovisión más tradicional que el proyecto político que la acompañaba, esperaban de ella.

Por otra parte, y sobre todo durante el reinado de Isabel II, la corte fue, además, un espacio para la fusión de las viejas y las nuevas élites. Acceder a la corte en la España del siglo XIX no era cosa fácil. Sin embargo, quien conseguía ingresar en tan prestigioso entorno formaba parte de un círculo muy exclusivo. Si bien no todos se hallaban en disposición de brillar de la misma forma, aquellos que por título o por fortuna lograron un papel protagonista en él alcanzaron una influencia indudable. La vida social de estos individuos que giraban alrededor de la figura real no solo fue un escaparate del grado de distinción social alcanzado, sino una forma de trazar redes de poder e influencia, de apoyos mutuos, que se proyectaba sobre el mundo de los negocios y sobre la política. De este modo, y por lo que se refiere a la alta burguesía, la burguesía de los negocios, no puede hablarse de una separación

48 Marqués de Lema, De la Revolución a la Restauración (Madrid: Editorial Voluntad, 1927): II, 451. Esa «atmósfera de economía burguesa» del Palacio Real en tiempos de Amadeo se revelaba «entre otros signos, en la iluminación deficiente y en la parquedad de la mesa». 
estricta entre sociabilidad cortesana y sociabilidad burguesa, pues ambas se hallaban estrechamente relacionadas. 


\section{REFERENCIAS BIBLIOGRÁFICAS}

Agulhon, Maurice, El círculo burgués. La sociabilidad en Francia, 1810-1848 (Buenos Aires: Siglo XXI, 2009).

Agulhon, Maurice, Política, imágenes, sociabilidades de 1789 a 1989 (Zaragoza: Prensas de la Universidad de Zaragoza, 2016).

Arnabat, Ramón y Montserrat Duch, coords., Historia de la sociabilidad contemporánea. Del asociacionismo a las redes sociales (Valencia: Universitat de València, 2014).

Bagehot, Walter, The English Constitution (Londres: Chapman and Hall, 1867).

Bermejo, Ildefonso, La Estafeta de Palacio (Historia del último reinado). Cartas trascendentales dirigidas al Rey Amadeo (Madrid: Imprenta de R. Labajos, 18711872, 3 vols.).

Bolaños Mejías, Carmen, «La casa real de Amadeo I de Saboya: rasgos organizativos», en $\mathrm{M}^{a}$ Dolores del Mar Sánchez González, coord., Corte y monarquía en España (Madrid: Centro de Estudios Ramón Areces, 2003).

Burdiel, Isabel, Isabel II (Madrid: Taurus, 2010).

Burguera, Mónica, «"Al ángel regio”. Respetabilidad femenina y monarquía constitucional en la España posrevolucionaria», en Encarna García Monerris, Mónica Moreno y Juan I. Marcuello, coords., Culturas políticas monárquicas en la España liberal (Valencia: Universitat de València, 2013): 131-150.

Calderón de la Barca, Frances, Un diplomático en Madrid. Impresiones sobre la corte de Isabel II y la revolución de 1854 (Zaragoza: Institución Fernando el Católico, 2018).

Cannadine, David, «Contexto, representación y significado del ritual: la monarquía británica y la invención de la tradición, c. 1820-1977», en Eric Hobsbawm y Terence Ranger, eds., La invención de la tradición (Barcelona, Crítica, 2012): 107171.

Casado, Ma Ángeles, «María Cristina de Borbón. Una regente cuestionada», en Emilio La Parra, coord., La imagen del poder. Reyes y regentes en la España del siglo XIX (Madrid: Síntesis, 2011): 133-176.

Cruz Valenciano, Jesús, Los notables de Madrid. Las bases sociales de la revolución liberal española (Madrid: Alianza, 2000). 
Cruz Valenciano, Jesús, El surgimiento de la cultura burguesa. Personas, hogares y ciudades en la España del siglo XIX (Madrid: Siglo XXI, 2014).

Elias, Norbert, La sociedad cortesana (Madrid: FCE, 1993).

Espoz y Mina, Condesa de, Memorias (Madrid: Tebas, 1977).

Fernández de Córdova, Fernando, Mis memorias intimas (Madrid: Establecimiento Tipográfico Sucesores de Rivadeneyra, 1886-1889, 3 vols.).

García Castañeda, Salvador, «Ecos de sociedad: la vida cortesana isabelina (18421846) que vio Washington Irving», en Dolores Thion, coord., El costumbrismo, nuevas luces (Pau: Presses de l'Université de Pau, 2013): 233-250.

Guardia Herrero, Carmen de la, «Las culturas de la sociabilidad y la transformación de lo político», en María Cruz Romeo y María Sierra, coords., La España Liberal, 1833-1874, Madrid, Marcial Pons-Prensas de la Universidad de Zaragoza, 2014.

Guereña, Jean-Louis, «Espacios y formas de la sociabilidad en la España contemporánea. Introducción», Hispania, 214 (2003): 409-414. DOI: https://doi.org/10.3989/hispania.2003.v63.i214.217

Hoyos, Antonio de, El primer estado. Actuación de la aristocracia antes de la revolución, en la revolución y después de ella (Madrid: $\mathrm{Rh}+, 2013)$.

Kirsh, Martin, «La trasformazione politica del monarca europeo nel XIX secolo», Scienzia \& Politica, 34 (2006): 22-35. DOI: 10.6092/issn.1825-9618/2849

Lema, marqués de, De la Revolución a la Restauración (Madrid: Editorial Voluntad, 1927).

Mauduit, Xavier, Le Ministère du faste. La Maison de l'empereur Napoléon III (Paris: Fayard, 2016).

Maza Zorrilla, Elena, coord., Sociabilidad en la España Contemporánea. Historiografía y problemas metodológicos (Valladolid: Universidad de Valladolid, 2002).

Mayer, Arno J., La persistencia del Antiguo Régimen (Madrid: Alianza Editorial, 1986).

Mera, Guadalupe, El baile en el Madrid romántico (1833-1868): prácticas de sociabilidad, repertorio coreográfico y recepción literaria (Oviedo: Universidad de Oviedo, 2015).

Mesonero Romanos, Ramón, Memorias de un setentón (Madrid: Editorial Castalia, 1994). 
Mira Abad, Alicia, «La imagen de la Monarquía o cómo hacerla presente entre sus súbditos: Amadeo y María Victoria», Mélanges de la Casa de Velázquez, 37/2 (2007): 173-198. DOI: $10.4000 /$ mcv.1743

Moral Roncal, Antonio, ;El enemigo en Palacio! Afrancesados, liberales y carlistas en la Real Casa y Patrimonio (1814-1843) (Alcalá de Henares: Universidad de Alcalá, 2005).

Moral Roncal, Antonio, «La Real Casa y Patrimonio en el reinado de Fernando VII (1814-1833)», en Raquel Sánchez y David San Narciso, coords., La cuestión de Palacio. Corte y cortesanos en la España contemporánea (Granada: Comares, 2018): 155-183.

Olmos, José Francisco y David Ramírez Jiménez, Los títulos nobiliarios durante el Sexenio Revolucionario (1868-1874) (Madrid: Real Academia Matritense de Heráldica y Genealogía, 2017).

Pascual Sastre, Isabel Mª «La corte bajo una constitución democrática. La Casa Real en el reinado de Amadeo I», en Raquel Sánchez y David San Narciso, coords., La cuestión de Palacio. Corte y cortesanos en la España contemporánea (Granada: Comares, 2018): 263-299.

Prado, Cristina del, El todo Madrid. La corte, la nobleza y sus espacios de sociabilidad en el siglo XIX (Madrid: Fundación Universitaria Española, 2012).

Prado, Cristina del, «Los salones de la nobleza española durante el reinado de Amadeo I», Aportes, 91 (2016): 27-56.

Pro, Juan, «Poder político y poder económico en el Madrid de los moderados (18441854)», Ayer, 66 (2007): 27-55.

Proyecto de Reglamento de Etiqueta Interior y Exterior del Real Palacio (Madrid: Imprenta Nacional, 1863).

Ridolfi, Mauricio, «Las fiestas nacionales: religiones de la patria y rituales políticos en la Europa liberal del "largo siglo XIX"), Pasado y memoria, 3 (2004): 135-154. DOI: $10.14198 /$ PASADO2004.3.08

Rodríguez Ruiz de la Escalera, Eugenio (Monte Cristo), Los salones de Madrid (Madrid: Ediciones 19, 2014 -1898-).

Romanones, Conde de, Amadeo de Saboya. El rey efimero (Madrid: Espasa Calpe, 1935).

Rueda, Germán, coord., La nobleza española, 1780-1930 (Madrid: Ediciones 19, 2014). 
San Narciso, David, «Ceremonias de la monarquía isabelina. Un análisis desde la historia cultural», Revista de historiografía, 21 (2014): 191-207.

San Narciso, David, «Celebrar el futuro, venerar la Monarquía. El nacimiento del heredero y el punto de fuga ceremonial de la monarquía isabelina (18571858)», Hispania, 77/255 (2017): 185-215. DOI: 10.3989/hispania.2017.007

Sánchez, Raquel, ed. dossier, El Poder informal: la corte como escenario Politico en España (1833-1885), Aportes, 33/96 (2018).

Sánchez, Raquel y David San Narciso, coords., La cuestión de Palacio. Corte y cortesanos en la España contemporánea (Granada: Comares, 2018).

Sánchez, Raquel y David San Narciso, «Fiesta en Palacio, revolución en la calle, estudio introductorio a Un diplomático en Madrid (1853-1854)», en Frances Calderón de la Barca, Un diplomático en Madrid. Impresiones sobre la corte de Isabel II y la revolución de 1854 (Zaragoza: Institución Fernando el Católico, 2018): IX-LXXXIII.

Sánchez, Raquel, «Política de gestos. La aristocracia contra la monarquía democrática de Amadeo», Pasado y memoria, 18 (2019): 19-38. DOI: 10.14198/PASADO2019.18.02

Sánchez, Raquel, coord. dossier, Hacia una monarquía nacional: la Corona como agente de nacionalización en España (1833-1885), Hispania, LXXIX/262 (2019).

Sánchez, Raquel, ed., Un rey para el pueblo. Monarquía y nacionalización en el siglo XIX (Madrid: Sílex, 2019).

Valdeiglesias, Marqués de, Setenta años de periodismo. Memorias (Madrid: Biblioteca Nueva, 1949-1952, 3 vols.).

Varela, Javier, La muerte del rey: el ceremonial funerario de la monarquía española, 1500-1885 (Madrid: Turner, 1990).

Villacorta, Francisco, «Sobre un viejo escenario: reina, corte y cortesanos en representación», en Juan Sisinio Pérez Garzón, ed., Isabel II: los espejos de la reina (Madrid: Marcial Pons, 2004): 282-297.

Zozaya Montes, María, El Casino de Madrid: ocio, sociabilidad, identidad y representación social (Madrid: UCM, 2008). 
Recibido: 14 de enero de 2020

Aprobado: 1 de marzo de 2020 